\title{
Lacrimal ductal cyst of the medial orbit: a case report
}

\author{
Yu Zhang, Changhong Zeng, Ningshao Chen and Chunling Liu* (1)
}

\begin{abstract}
Background: The lacrimal ductal cyst (dacryops) is an uncommon clinical entity. It occurs anywhere that lacrimal gland tissue is present but most often appears as an expanding mass in the region of the lacrimal gland. The presence involving the medial part of the orbit is rare, ectopic location can be misleading in the differential diagnosis of orbital masses. The authors report a 53-year-old man who presented with dacryops occurred in an unusual location with significant clinical presentations.

Case presentation: A 53-year-old man had a painless mass located in the right superomedial orbit accompanied with foreign body sensation and lachrymation for two months, which had rapidly grown within 10 days. Decrease of visual acuity, high intraocular pressure (IOP) and limitation of extraocular movements in the right eye were present. The result of visual evoked potential (VEP) test suggested the impaired function of the optic nerve. Magnetic resonance imaging (MRI) studies revealed the presence of an isolated cystic lesion. The mass was completely removed via a transcutaneous approach, histopathologic findings were consistent with the lacrimal ductal cyst. The ocular motility and high IOP returned to normal. There had been no post-operative complications or signs of recurrence over five months follow-up.

Conclusion: Lacrimal ductal cysts can present in the medial orbit, clinicians should include this entity in the differential diagnosis of orbital masses and be aware of its variable presentations such as high IOP in this case. We comment on the fact that many reported cases of ectopic dacryops may be an extension of normal lacrimal gland tissue.
\end{abstract}

Keywords: Lacrimal ductal cyst, Dacryops, Intraorbital mass, Intraocular pressure

\section{Background}

The lacrimal ductal cyst (dacryops) is a benign epithelial tumor of the lacrimal tissue, which usually locates in the outer part of the upper eyelid presenting to be an asymptomatic, smooth, mobile and fluctuant swelling [1]. Ectopic dacryops is lacrimal ductal cyst located at any site other than the normal. The presence involving the medial part of the orbit is very rare [1-4]. These cysts may cause mechanical blepharoptosis, proptosis, mechanical restriction of the ocular motility and diplopia $[5,6]$. Secondary high intraocular pressure due to

\footnotetext{
* Correspondence: chunlingt@163.com

Department of Ophthalmology, West China Hospital, Sichuan University,

Chengdu 610041, Sichuan, People's Republic of China
}

dacryops has not been reported previously. Herein, the authors report a case of ectopic dacryops in the medial orbit.

\section{Case presentation}

A 53-year-old man complained of a painless swelling of the right upper lid for 2 months accompanied with foreign body sensation and lachrymation. The mass had rapidly developed within 10 days, which could be enlarged and purplish blue after rubbing the eye. The patient denied the history of trauma, infection or surgery. A cystic mass could be felt at the superior-medial of the orbit, which was smooth, mobile, fluctuant and without tenderness. There was some underactive motility when

(C) The Author(s). 2020 Open Access This article is licensed under a Creative Commons Attribution 4.0 International License, which permits use, sharing, adaptation, distribution and reproduction in any medium or format, as long as you give appropriate credit to the original author(s) and the source, provide a link to the Creative Commons licence, and indicate if changes were made. The images or other third party material in this article are included in the article's Creative Commons licence, unless indicated otherwise in a credit line to the material. If material is not included in the article's Creative Commons licence and your intended use is not permitted by statutory regulation or exceeds the permitted use, you will need to obtain permission directly from the copyright holder. To view a copy of this licence, visit http://creativecommons.org/licenses/by/4.0/ The Creative Commons Public Domain Dedication waiver (http://creativecommons.org/publicdomain/zero/1.0/) applies to the data made available in this article, unless otherwise stated in a credit line to the data. 


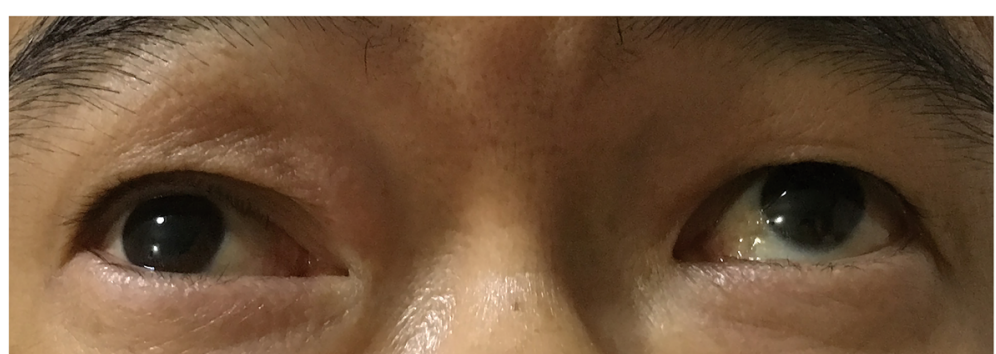

Fig. 1 External appearance. A 53-year-old man with a painless mass in the right superior medial orbit. The right eye had difficulty in superior motility

the patient looked upward (Fig. 1). No mass was evident on everting the upper lid. The anterior segment and fundus examination were normal. The corrected visual acuity in the right eye was $12 / 20$ and was $20 / 20$ in the left eye, the intraocular pressure (IOP) is $36 \mathrm{mmHg}$ and 18 $\mathrm{mmHg}$ respectively. The anterior segment and fundus examination were normal. Visual evoked potential (VEP) test showed significant delay of the P100 component peak time in the right eye for $19.8 \mathrm{~ms}$. Axial magnetic resonance imaging (MRI) studies revealed the presence of an isolated $16.2 \times 13.7 \mathrm{~mm}$ cystic lesion occupying the superior right orbit, adjacent to the trochlea and superior oblique muscle. The content of the cyst showed medium intensity on $\mathrm{T} 1$ and hyperintensity $\mathrm{T} 2$ weighted imaging (Fig. 2). Under general anesthesia, we performed a surgical excision through a transcutaneous approach. Intraoperatively, the cyst was found extending posteriorly behind the orbital septum, with mild adhesion to surrounding tissues. It ruptured during removal separation towards the conjunctiva and spilled out clear, colourless, thin watery fluid, similar to tears. The cyst wall was completely excised and a reconstructive conjunctivoplasty was performed. The specimen consisted of a collapsed cyst measuring $18 \mathrm{~mm} \times 10 \mathrm{~mm} \times 5 \mathrm{~mm}$, the cyst wall was about $0.1-0.2 \mathrm{~mm}$. On light microscopy, the surface of the capsule was lined with double cubic epithelium. Noticeable apocrine differentiation was evident as the epithelium seems to present villous projections into the lumen at its apex. Adjacent to the cyst wall contained a mild to moderate chronic inflammatory cell infiltration. Lacrimal gland tissue was found. (Fig. 3) The final diagnosis was consistent with a cyst of ductal origin. The first day after the operation, the corrected visual acuity was $20 / 20$ in both eyes, the IOP was 18.2 $\mathrm{mmHg}$ in the right eye and $18.4 \mathrm{mmHg}$ in the left eye, the ocular motility returned to normal. There had been no post-operative complications or signs of recurrence over a five-month follow-up.

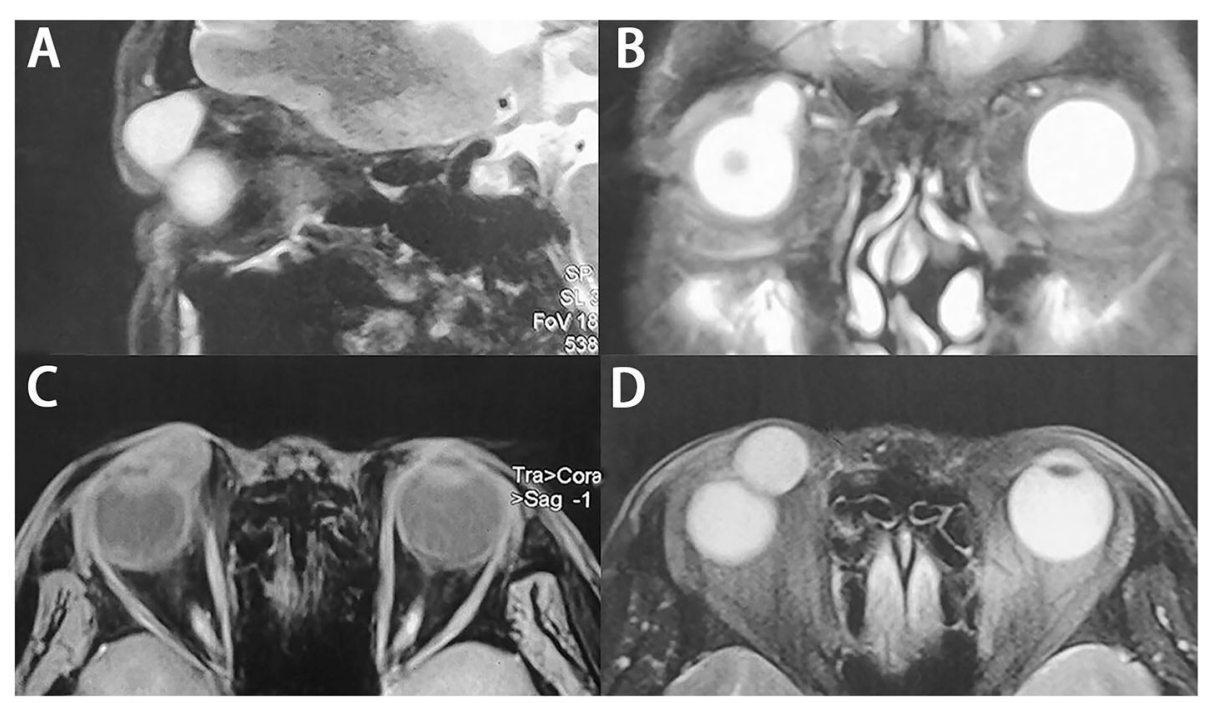

Fig. 2 Magnetic resonance imaging shows a fluid-density cyst in the right superior medial orbit. a, Sagittal plane, b, Coronal plane, c, Axial plane T1weighted, d, Axial plane T2weighted 


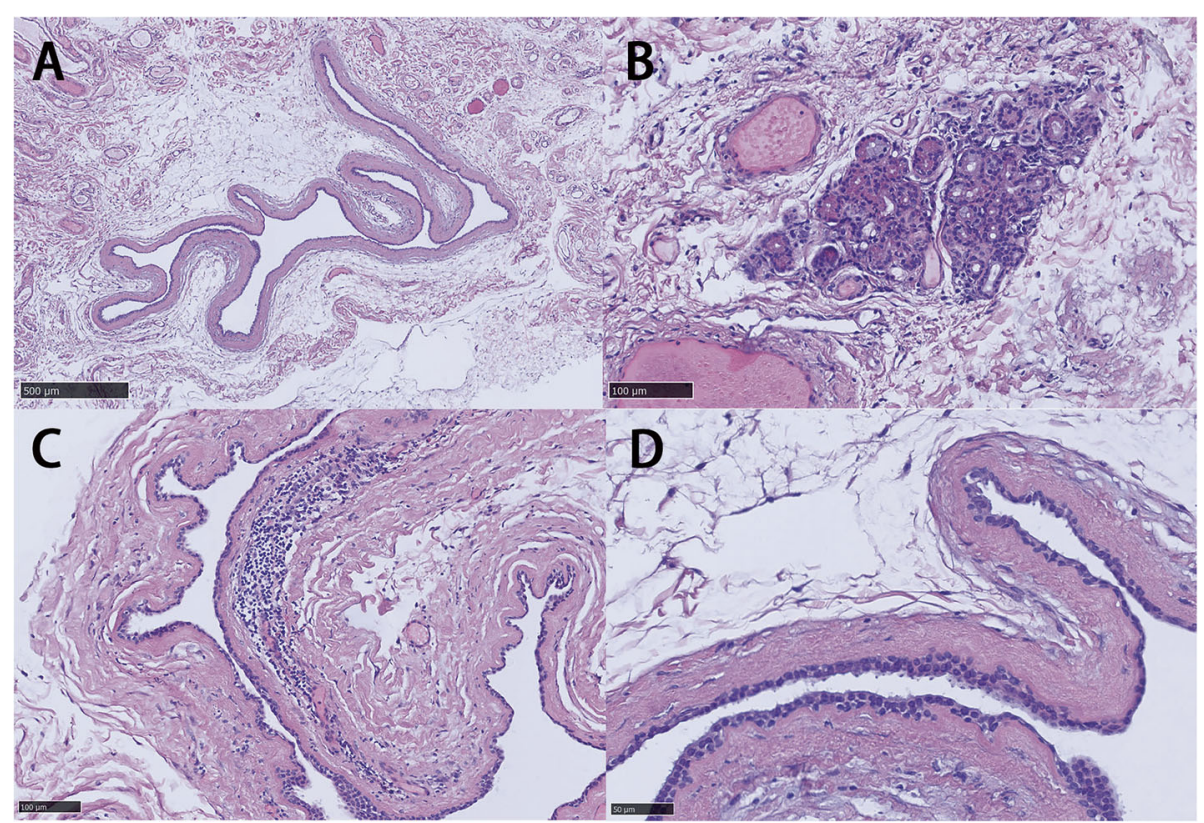

Fig. 3 Histopathology of the dacryops. a, A large cystic area lined with two layers of cuboidal epithelium similar to that of lacrimal ductal structures. Note absence of Goblet cells (hematoxylin and eosin staining, original magnification, $\times 50$ ). $\mathbf{b}$, Glandular tissue (hematoxylin and eosin staining, original magnification, $\times 200$ ). c, Adjacent to the cyst wall contains a mild to moderate chronic inflammatory cell infiltration (hematoxylin and eosin staining, original magnification, $\times 200$ ). $\mathbf{d}$, The apical changes of apocrine secretion. (hematoxylin and eosin staining, original magnification, $\times 400$ )

\section{Discussion and conclusion}

Lacrimal ductal cyst is not common, from studies in Wills Eye Hospital by Shields et al,it accounts for up to $2 \%$ of all orbital mass and $6 \%$ of lacrimal gland lesions $[7,8]$. The term dacryops for cysts of the palpebral lobe was introduced by Schmidt in 1803, which has been extended to describe lacrimal gland cysts of other kinds. Typically, they present at the superotemporal eyelid fornix where the most lacrimal gland tissue is present. Bullock proposed a classification system based on the location of the lacrimal gland tissue: palpebral lobe cysts (simple dacryops); orbital lobe cysts; cysts of the accessory lacrimal glands of Krause and Wolfring; and cysts of ectopic (choristomatous) lacrimal glands [1].

Among all forms of dacryops from the literature, simple dacryops is the most common which often protrude into the lateral upper fornix $[1,9,10]$. Orbital lobe cysts tend to present in infancy and early childhood, deep in the orbit producing proptosis and inferonasal displacement of the globe $[1,3]$. Krause glands located within the fornix, while Wolfring glands are adherent or adjacent to the proximal tarsal border of the eyelids. Cysts of accessory lacrimal gland are generally to be found in the conjunctiva of the fornix [11, 12]. Ectopic lacrimal gland tissue has been reported to occur in in the eyelid, outer canthus, conjunctiva, sclera, caruncle, cornea, iris, choroid,and the orbit $[1,2,11]$. Alyahya et al. reported the largest series of ectopic lacrimal gland describing 61 such cases, all the cases were located temporally [13] . The presence involving the medial part of the orbit is rare. It is difficult to firstly consider the lacimal gland origin when a cyst occurs in the medial orbit. Clues to the diagnosis are both anatomic and histopathologic [11, 14]. However, in this patient it is difficult to distinguish ectopic dacryops with accessory lacrimal gland cysts for the histopathologic appearance is identical regardless of origin and location [15]. It was seldom diagnosed accurately for many reports in the literature were both confusing and inaccurate. There was a similar case of ectopic dacryops above the orbit was later thought to be a Wolfring's accessory lacrimal gland cyst $[11,16]$. Many other authors share this same opinion that many reported cases of ectopic dacryops might be an extension of normal lacrimal gland tissue [17].. By definition, we believe the lesion in this patient is ectopic dacryops because of the unusual anatomic location in the deep orbit and the histological assessment. Nevertheless, whether the possible source is the accessory lacrimal gland or ectopic lacrimal tissue (choristomas) is difficult to say.

The pathogenesis for the development of dacryops is still unclear. It has been reported associated with trachoma, conjunctival inflammation, ocular cicatricial pemphigoid, high levels of IgA, prolapse of the lacrimal gland, ocular trauma and chemical injury $[11,15,18]$. Initial reports proposed mechanical blockage theory and impaired ductal myoepithelial contractility, others proposed that a combination of periductal inflammation 
and trauma and a dysfunction of the rich neural plexus and hypersecretion may cause cyst formation [12, 19, 20]. The findings of apocrine changes, lymphoid tissue and lachrymation in this case may help to explain the pathogenesis of the disease.

Dacryops is usually asymptomatic and insidious, which can grow rapidly in the context of infection [21].. The chronic progression is capable of undergoing malignant transformation [22].. There are no definite guidelines for treatment. Most reports recommend observation if the tumor is silent and the cysts are not progressively enlarging. The indications for surgical treatment include diplopia, blepharoptosis, pain, chronic irritation or infection [21]. The clinical manifestations in this case included tears, limitation of extraocular movements, decrease of visual acuity, high intraocular pressure, and rapid growth of dacryops. With the mass grew rapidly, short-term high IOP resulted to early impairment of the innermost retinal layers, notwithstanding a normal optic disc and visual field analysis [23]. The examination first presented the latency of P100 waves. The compression of optic nerve was revealed by the VEP abnormalities in this case, which might be overlooked in the past. The rapid progress and significantly increased IOP prompted the authors to perform the surgery, so as to confirm the diagnosis and avoid further optic nerve injury. Considering the mass was located in the anterior superior medial orbit close to the trochlea, the author took an orbitotomy through a transcutaneous approach. The ocular motility, visual acuity and high intraocular pressure returned to normal after the operation. Complete excision of dacryops is generally recommended to reduce the risk of recurrence $[11,12,15]$.

In conclusion, we describe an uncommon lacrimal ductal cyst in an atypical location, which should be considered in the differential diagnosis of medial orbital masses. Although the dacryops presents as benign tumor, the mass effects deserve attention for treatment.

\section{Abbreviations}

IOP: Intraocular pressure; VEP: Visual evoked potential; MRI: Magnetic resonance imaging

\section{Acknowledgements}

Not applicable.

\section{Authors' contributions}

$Y Z$ was major contributor to the drafting of the manuscript. $Y Z, N C$ and $C Z$ collected and interpreted the ophthalmic data. CZ performed the surgical treatment and wrote the histology part. CL reviewed and edited the manuscript. All authors reviewed and approved the final manuscript.

\section{Funding}

Not applicable.

\section{Availability of data and materials}

Not applicable.

Ethics approval and consent to participate Not applicable.

\section{Consent for publication}

The patient gave written consent for clinical details and images to be published in this journal. A copy of the written consent is available for review by the Editor of this journal.

\section{Competing interests}

The authors declare that they have no competing interests.

Received: 26 February 2020 Accepted: 7 September 2020

Published online: 24 September 2020

\section{References}

1. Bullock JD, Fleishman JA, Rosset JS. Lacrimal ductal cysts. Ophthalmology. 1986;93(10):1355-60.

2. Rush A, Leone CR. Ectopic lacrimal gland cyst of the orbit. Am J Ophthalmol. 1981;92(2):198-201.

3. von Domarus H. A lacrimal gland cyst in the orbit. J Craniomaxillofac Surg. 1987;15(2):106-9.

4. Lenzi R, Casani AP, Sellari-Franceschini S. Ectopic intraorbital lacrimal ductal cyst: a case report. Orbit. 2012;31(5):350-1.

5. Duman R, Duman R, Balci M. Diplopia due to Dacryops. Case Rep Ophthalmol Med. 2013;2013:549487.

6. Nakauchi K, Katori N, Imagawa Y, Yamada T. A case report on lacrimal ducta cyst causing unilateral blepharoptosis. Br J Ophthalmol. 2009;93(9):1143-5.

7. Shields CL, Shields JA, Eagle RC, Rathmell JP. Clinicopathologic review of 142 cases of lacrimal gland lesions. Ophthalmology. 1989;96(4):431-5.

8. Shields JA, Shields CL, Scartozzi R. Survey of 1264 patients with orbital tumors and simulating lesions: the 2002 Montgomery lecture, part 1. Ophthalmology. 2004;111(5):997-1008.

9. Ozgonul C, Uysal Y, Ayyildiz O, Kucukevcilioglu M. Clinical features and management of dacryops. Orbit. 2018;37(4):262-5.

10. Betharia SM, Pushker N, Sharma V, Sen S. Simple dacryops: a case series and review of the literature. Ophthalmologica. 2002;216(5):372-6.

11. Weatherhead RG. Wolfring Dacryops. Ophthalmology. 1992;99(10):1575-81.

12. Jakobiec FA, Zakka FR, Perry LP. The cytologic composition of dacryops: an immunohistochemical investigation of 15 lesions compared to the normal lacrimal gland. Am J Ophthalmol. 2013;155(2):380-96.

13. Alyahya GA, Bangsgaard R, Prause JU, Heegaard S. Occurrence of lacrimal gland tissue outside the lacrimal fossa: comparison of clinical and histopathological findings. Acta Ophthalmol Scand. 2005;83(1):100-3.

14. Lam K, Brownstein S, Jordan DR, Jastrzebski A. Dacryops: a series of 5 cases and a proposed pathogenesis. JAMA Ophthalmol. 2013;131(7):929-32.

15. Galindo-Ferreiro A, Alkatan HM, Muinos-Diaz Y, Akaishi PM, Galvez-Ruiz A, Cruz AV. Accessory lacrimal gland duct cyst: 23 years of experience in the Saudi population. Ann Saudi Med. 2015;35(5):394-9.

16. Brownstein S, Belin MW, Krohel GB, Smith RS, Condon G, Codere F. Orbital Dacryops. Ophthalmology. 1984;91(11):1424-8.

17. Braich PS, Silbert JE, Levada AJ, Schiff NR. Pseudo third cranial nerve palsy secondary to orbital ectopic lacrimal gland cyst: management with functional endoscopic sinus surgery. Ear, Nose, Throat J. 2014;93(2):77-9.

18. Morgan-Warren PJ, Madge SN. Lacrimal duct cyst (dacryops) following ocular chemical injury. Orbit (Amsterdam, Netherlands). 2012;31(5):335-7.

19. Tsiouris AJ, Deshmukh M, Sanelli PC, Brazzo BG. Bilateral dacryops: correlation of clinical, radiologic, and histopathologic features. AJR Am J Roentgenol. 2005;184(1):321-3.

20. Kacerovska D, Michal M, Ricarova R, Frdlikova D, Sosna B, Kazakov DV. Apocrine secretion in lacrimal gland cysts (dacryops): a common but underrecognized phenomenon. J Cutan Pathol. 2011;38(9):720-3.

21. Kurup SP, Lissner GS. Characterization of dacryops infections. Ophthal Plast Reconstr Surg. 2015;31(1):58-62.

22. Su GW, Patipa M, Font RL. Primary squamous cell carcinoma arising from an epithelium-lined cyst of the lacrimal gland. Ophthal Plast Reconstr Surg. 2005:21(5):383-5.

23. Parisi V, Miglior S, Manni G, Centofanti M, Bucci MGJO. Clinical ability of pattern electroretinograms and visual evoked potentials in detecting visual dysfunction in ocular hypertension and glaucoma. Ophthalmology. 2006; 113(2):216-28.

\section{Publisher's Note}

Springer Nature remains neutral with regard to jurisdictional claims in published maps and institutional affiliations. 